\title{
Electron energy-loss spectrometry on lithiated graphite
}

\author{
A. Hightower, C. C. Ahn, ${ }^{\text {a) }}$ and B. Fultz \\ Division of Engineering and Applied Science, California Institute of Technology, Pasadena, California 91125 \\ P. Rez \\ Department of Physics and Astronomy, Arizona State University, Tempe, Arizona 85287
}

(Received 29 November 1999; accepted for publication 23 May 2000)

\begin{abstract}
Transmission electron energy-loss spectrometry was used to investigate the electronic states of metallic $\mathrm{Li}$ and $\mathrm{LiC}_{6}$, which is the Li-intercalated graphite used in Li-ion batteries. The $\mathrm{Li} K$ edges of metallic $\mathrm{Li}$ and $\mathrm{LiC}_{6}$ were nearly identical, and the $\mathrm{C} K$ edges were only weakly affected by the presence of $\mathrm{Li}$. These results suggest only a small charge transfer from $\mathrm{Li}$ to $\mathrm{C}$ in $\mathrm{LiC}_{6}$, contrary to prior results from surface spectra obtained by x-ray photoelectron spectroscopy. Effects of radiation damage and sample oxidation in the transmission electron microscopy are also reported. (C) 2000 American Institute of Physics. [S0003-6951(00)04428-4]
\end{abstract}

Lithiated graphite is the standard anode material in $\mathrm{Li}-$ ion rechargeable batteries. ${ }^{1}$ Highly crystallized graphite can intercalate $\mathrm{Li}$ atom to a maximum composition of $\mathrm{LiC}_{6}$. This is equivalent to a specific charge of $372 \mathrm{Ah} \mathrm{kg}^{-1},{ }^{2}$ although in practice graphite anodes have specific energies of $320-360 \mathrm{Ah} \mathrm{kg}^{-1}$. Graphite anodes have high voltages of 3-4 V versus the cathode, but the difference in electrochemical potential between metallic $\mathrm{Li}$ and lithiated graphite is small, of order $0.01 \mathrm{~V}$. The intercalation of Li into highly crystallized graphite changes the stacking sequence of the hexagonal planes from an ABABAB to AAAAAA. ${ }^{3}$ This change in stacking sequence and the high chemical potential of $\mathrm{Li}$ in graphite suggest that a better understanding of the interlayer states of $\mathrm{LiC}_{6}$ may facilitate improvements to $\mathrm{Li}$ ion electrochemical cells.

The results of numerous studies on the band structure of $\mathrm{Li}$ intercalated graphite demonstrate the difficulty in determining the degree of hybridization between $\mathrm{Li}$ atomic orbitals and graphite interlayer states. Early theoretical calculations of the $\mathrm{LiC}_{6}$ band structure began with the notion of complete charge transfer of $\mathrm{Li}$ valence electrons to the graphite $p$ bands. ${ }^{4,5}$ This evolved into an elegant theory of alkali-intercalated graphite interlayer states as interacting nonorthogonal hybrid states of $\mathrm{Li} 2 s$ and graphite interlayer states. ${ }^{6,7}$ This gives credence to $\mathrm{X}$-ray photoelectron spectroscopy (XPS) results by Momose $e t a l^{8}$ and others ${ }^{9}$ claiming $\mathrm{Li}$ to be intercalated into graphite as ionic $\mathrm{Li}^{+}$. Early experimental work by Grunes et al. ${ }^{10}$ using electron energy-loss spectroscopy (EELS) demonstrated distortions of the graphite band structure upon intercalation of alkali metals. Hartwigsen et al. ${ }^{11}$ used a density functional theory, local density approximation to determine the degree of charge transfer from $\mathrm{Li}$ to the intercalant host lattice to be $0.5 \mathrm{e}$ for $\mathrm{LiC}_{6}$ and $0.4 \mathrm{e}$ for $\mathrm{LiC}_{8}$. Further experiments using inelastic $\mathrm{x}$-ray scattering spectroscopy by Schülke ${ }^{12}$ were able to correlate features of $\mathrm{LiC}_{6}$ spectra to band structure calculations by Holzwarth et al. ${ }^{13}$

The present letter reports transmission EELS measurements of the Li $K$ edge in intercalated graphite and in me-

a)Electronic mail: cca@caltech.edu tallic Li. After showing oxidation tendencies of the transmission electron microscopy (TEM) samples and how this was controlled, we show that the $\mathrm{Li} K$ edge for $\mathrm{Li}$ in $\mathrm{LiC}_{6}$ resembles the Li $K$ edge of neutral metallic Li rather than of $\mathrm{Li}^{+}$. We believe that the name "Li-ion" battery is therefore misleading.

$\mathrm{LiC}_{6}$ samples were prepared by electrochemical methods. ${ }^{14}$ Anodes were constructed from KS 44 graphite using $6 \mathrm{wt} \%$ poly(vinylidene fluoride) as a binder. A ternary mixture of aykyl carbonates, i.e., 1:1:1 of ethylene carbonate, diethylene carbonate, and dimethyl carbonate (DMC) with 1 $\mathrm{M} \mathrm{LiPF}_{6}$ was used as the electrolyte. Carbon half-cells were subjected to 40 electrochemical charge-discharge cycles. The carbon electrodes were left in a charged state before being washed in DMC and vacuum dried.

Thin samples of metallic $\mathrm{Li}$ and $\mathrm{LiF}$ were prepared by thermal evaporation onto amorphous holey carbon TEM grids. A glove bag filled with Ar gas was placed over the evaporator to minimize atmospheric exposure during transfers. The evaporating chamber was backfilled with Ar where the samples were immersed in Flourinert ${ }^{\circledR}$ FC-43, gettered with $\mathrm{Li}$ chips. The $\mathrm{LiC}_{6}$ samples were crushed with a mortar and pestle in an Ar-filled glove box. The powdered anode material was placed onto holey carbon TEM grids. The TEM grids were immersed in Li-gettered Flourinert FC-43 before insertion into the microscope load lock, where the Flourinert evaporated. Transmission EELS spectra were acquired at room temperature using a Gatan 666 parallel detection magnetic prism spectrometer attached to a Philips EM 420 transmission electron microscope. Energy resolution of the spectrometer was about $1.2 \mathrm{eV}$ with a dispersion of $0.2 \mathrm{eV}$ per channel. Measurements were performed with $100 \mathrm{keV}$ electrons at a collection angle of either 11 or $50 \mathrm{mrad}$. EELS spectra of the evaporated samples were acquired with image coupling. The $\mathrm{LiC}_{6}$ spectra were acquired with diffraction coupling. The TEM beam current was approximately $7 \mathrm{nA}$.

$\mathrm{X}$-ray diffractometry was performed with an Inel powder diffractometer using Mo $K_{\alpha}$ radiation $(\lambda=0.07092 \mathrm{~nm})$. Anode materials were sealed under Ar with paraffin wax in Pyrex capillary tubes. X-ray diffraction patterns, as shown in Fig. 1, confirmed the presence of $\mathrm{LiC}_{6}$ and $\mathrm{LiC}_{12}$ phases in 


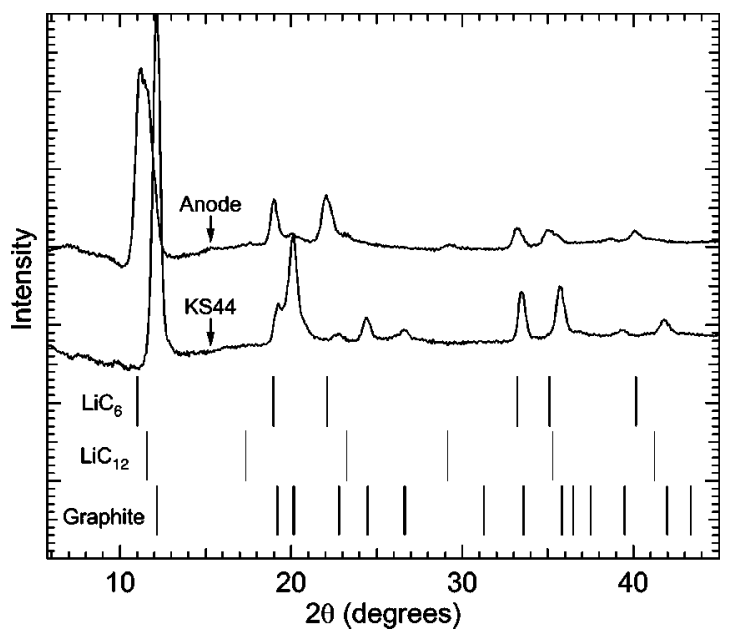

FIG. 1. X-ray diffraction patterns of KS 44 graphite and electrochemically lithated graphite containing $\mathrm{LiC}_{6}$ and $\mathrm{LiC}_{12}$ phases.

the graphite anode materials. These results were consistent with the color of lithiated graphite which depends on the predominance of $\mathrm{LiC}_{6}$ (green/gold) or $\mathrm{LiC}_{12}$ (blue/black). ${ }^{15}$ The diffraction peaks were broader for $\mathrm{LiC}_{6}$ than for the unlithiated KS 44 graphite samples.

The reactivity of reduced $\mathrm{Li}$ and its susceptibility to radiation damage under an electron beam present a formidable challenge to EELS analysis of $\mathrm{LiC}_{6}$. The majority of radiation damage is a result of the direct transfer of momentum from incident electrons to the Li nucleus, ejecting it from its lattice site. Average atomic displacement energies estimated from sublimation energies were found to be $6.1 \mathrm{eV}$ for $\mathrm{Li}$ and $31.2 \mathrm{eV}$ for $\mathrm{C}$ in graphite. ${ }^{16}$ Assuming elastic collisions, the knock-on damage, threshold energies for incident electrons are $19 \mathrm{keV}$ for $\mathrm{Li}$ and $150 \mathrm{keV}$ for $\mathrm{C}$. Metallic $\mathrm{Li}$ samples appeared to "boil" during TEM observations at 200 $\mathrm{keV}$. This was determined to be a consequence of knock-on damage since the calculated temperature rise was negligible, approximately $1 \mathrm{~K} .{ }^{17} \mathrm{We}$ chose a microscope voltage of 100 $\mathrm{keV}$ as a reasonable compromise between knock-on damage and instrument performance.

Beam damage of metallic Li was studied at $100 \mathrm{keV}$ by concentrating the electron beam onto a thin area of the $\mathrm{Li}$ sample. Figure 2 presents a time sequence of EELS spectra for this exposed region. Over a few minutes, the spectral area of the low-loss region was reduced significantly, resulting in the suppression of Li plasmons at 7.5 and $15 \mathrm{eV}$. This is consistent with a thinning of the sample as $\mathrm{Li}$ atoms are ejected from the sample under the electron beam. In image mode, regions of the specimen were observed to shrink, especially under a focused incident beam.

Over a slightly longer time scale under a focused beam, the Li plasmons evolved into distinct profiles commonly associated with oxidized Li. ${ }^{18}$ During this time, as shown in Fig. 2, the broad profile of the Li $K$ edge evolves into two sharp peaks at 59.5 and $64.5 \mathrm{eV}$, similar to peaks observed from samples exposed to atmosphere. ${ }^{18}$ Exposure to the intense electron beam stimulates $\mathrm{Li}$ reactions with moisture and oxygen present in the microscope, leading to the formation of $\mathrm{LiOH}$ and $\mathrm{Li}_{2} \mathrm{O} .{ }^{19}$ The $\mathrm{Li} K$ edge in our $\mathrm{LiC}_{6}$ samples showed the same peaks at 59.5 and $64.5 \mathrm{eV}$ after the samples were exposed to atmosphere.

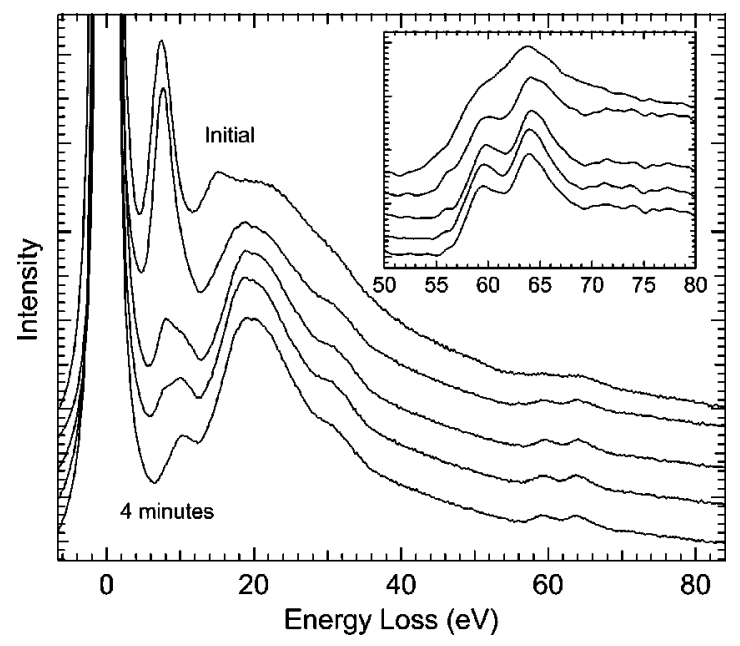

FIG. 2. EELS spectra of beam-damaged Li. Spectra were acquired at approximately equal intervals from nearly zero, to $4 \mathrm{~min}$ of electron beam exposure.

Figure 3 presents the $\mathrm{C} K$ edges of $\mathrm{LiC}_{6}$ and $\mathrm{KS} 44$ graphite. A peak at $301 \mathrm{eV}$ is found in $\mathrm{LiC}_{6}$ but not in the graphitic carbon. Disko ${ }^{20}$ and others ${ }^{21}$ have demonstrated the sensitivity of the $\mathrm{C} K$ edge to the direction of the momentum transfer vector $\mathbf{q}$. We therefore do not expect the intensity of the $1 s \rightarrow \pi^{*}$ peak to be reliable, since it is not an average over many crystal orientations. Nevertheless, the onset energy of the C $K$ edge and the location of the $1 s \rightarrow \pi^{*}$ peak are essentially the same for graphitic carbon and $\mathrm{LiC}_{6}$.

Figure 4 displays the Li $K$ edge obtained from intercalated $\mathrm{LiC}_{6}, \mathrm{LiF}$, and metallic $\mathrm{Li}$. We identify the onset of the Li $K$ edge in the metallic sample at $55 \mathrm{eV}$, consistent with results of Liu and Williams. ${ }^{18}$ The broad profile of the metallic Li $K$ edge is consistent with the promotion of core electrons into a continuum of free electron states. The $\mathrm{Li} K$ edge onset of $\mathrm{LiC}_{6}$ is shifted by only $0.2 \mathrm{eV}$ from the $K$ edge of metallic $\mathrm{Li}$ and has a similarly broad profile. Our observed Li $K$ edge for $\mathrm{LiC}_{6}$ lacks the peaks at 59 and $63 \mathrm{eV}$ previously observed by Grunes et al. ${ }^{10}$ These peaks evidently originate from oxidized $\mathrm{Li}$ - they are found in samples exposed to atmosphere, or after long times in the microscope (Fig. 2). The Li $K$ edge of LiF, similar to that reported by

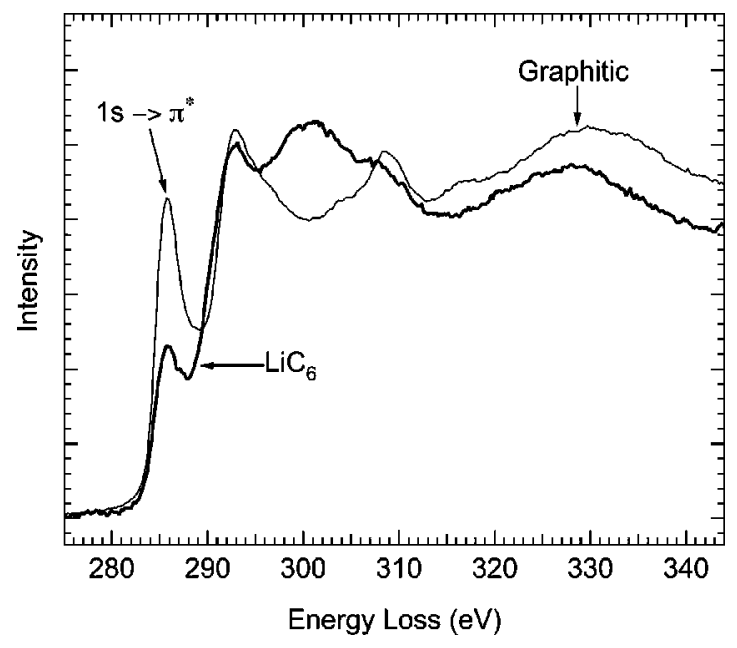

FIG. 3. C $K$ edge for $\mathrm{LiC}_{6}$ and $\mathrm{KS} 44$ graphite, normalized by the area 50

eV after edge onset.
AIP license or copyright, see http://apl.aip.org/apl/copyright.jsp 


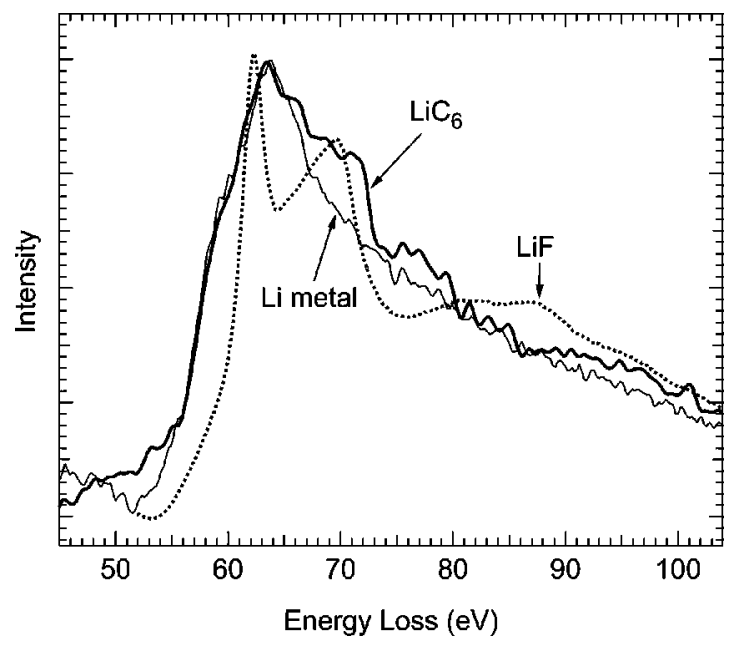

FIG. 4. $\mathrm{Li} K$ edge of metallic $\mathrm{Li}, \mathrm{LiC}_{6}$, and $\mathrm{LiF}$. The pre-edge background of the raw data was fit to an exponential and subtracted from the data.

Chen et al., ${ }^{22}$ shows a strong chemical shift and sharp features of well-defined unoccupied states. Such large differences are expected with the large electron transfer from $\mathrm{Li}$ to F.

Our EELS spectra of the $\mathrm{Li} K$ edge indicate that $\mathrm{Li}$ in $\mathrm{LiC}_{6}$ has a local electronic structure more similar to Li metal than $\mathrm{Li}^{+}$, contrary to previous XPS results. Extensive XPS results confirm a Li $K$ edge chemical shift of about $3 \mathrm{eV}$ in $\mathrm{LiC}_{6}$ with respect to metallic $\mathrm{Li}^{8,9}$ easily resolved from the $1.3 \mathrm{eV}$ chemical shift of $\mathrm{Li}_{2} \mathrm{O} .^{23}$ The mean free path of photoelectrons measured by XPS is on the order of $1 \mathrm{~nm}$. Thus, assuming that the surface $\mathrm{Li}$ remains unreacted, we expect XPS to be more sensitive to Li surface states.

The similarities of $\mathrm{Li} K$ edges in $\mathrm{LiC}_{6}$ and metallic $\mathrm{Li}$ are consistent with observed electrochemical potentials. Measurements of electrochemical potentials in half cells show $\mathrm{LiC}_{6}$ to be less than $0.01 \mathrm{~V}$ above $\mathrm{Li}$ metal. ${ }^{24}$ The similar chemical potentials of $\mathrm{Li}$ in $\mathrm{LiC}_{6}$ and metallic $\mathrm{Li}$ suggest similar environments for valence electrons. Electrochemical potentials and EELS Li $K$ edge profiles both suggest limited charge transfer from Li to surrounding carbon. The observed EELS C $K$ edge is little affected by intercalated $\mathrm{Li}$, but effects should be diminished by the 6:1 ratio of $\mathrm{C}$ to $\mathrm{Li}$, and could be diminished further if there were a loss of Li from the TEM sample. The shape of the Li $K$ edge, on the other hand, would be unaffected by any possible loss of $\mathrm{Li}$, or perhaps would appear even more ionic, since the electrochemical potential of $\mathrm{Li}$ would be lowered.

This work was supported by DOE through Basic Energy Sciences Grant No. DE-FG03-94ER14493.

${ }^{1}$ A. Hérold, Bull. Soc. Chim. Fr. 187, 999 (1955).

${ }^{2}$ M. S. Dresselhaus and G. Dresselhaus, Adv. Phys. 30, 139 (1980).

${ }^{3}$ J. R. Dahn, A. K. Sleigh, H. Shi, B. M. Weydanz, J. N. Reimers, Q. Zhong, and U. von Sacken, in Lithium Batteries: New Materials, Developments and Perspectives, edited by G. Pistoia (Elsevier, Amsterdam, 1994), p. 1.

${ }^{4}$ N. A. W. Holzwarth, S. G. Louie, and S. Rabii, Phys. Rev. B 26, 5382 (1982).

${ }^{5}$ J. J. Ritsko, Phys. Rev. B 25, 6452 (1982).

${ }^{6}$ N. A. W. Holzwarth, S. G. Louie, and S. Rabii, Phys. Rev. B 30, 2219 (1984).

${ }^{7}$ M. Posternak, A. Baldereschi, A. J. Freeman, E. Wimmer, and M. Weinert, Phys. Rev. Lett. 50, 761 (1983).

${ }^{8}$ H. Momose, H. Honbo, S. Takeuchi, K. Nishimura, T. Horiba, Y. Muranaka, Y. Kozono, and H. Miyadera, J. Power Sources 68, 208 (1997).

${ }^{9}$ G. K. Wertheim, P. M. Th. M. Vanattekum, and S. Basu, Solid State Commun. 33, 1127 (1979).

${ }^{10}$ L. A. Grunes, I. P. Gates, J. J. Ritsko, E. J. Mele, D. P. DiVincenzo, M. E. Preil, and J. E. Fische, Phys. Rev. B 28, 6681 (1983).

${ }^{11}$ C. Hartwigsen, W. Witschel, and E. Spohr, Phys. Rev. B 55, 4953 (1997).

${ }^{12}$ W. Shülke, A. Berthold, A. Kaprolat, and H. J. Guntherodt, Phys. Rev. Lett. 60, 2217 (1988).

${ }^{13}$ N. A. W. Holzwarth, S. G. Louie, and S. Rabii, Phys. Rev. B 28, 1013 (1983).

${ }^{14}$ M. C. Smart, B. V. Ratnakumar, S. Surampudi, Y. Wang, X. Zhang, S. G. Greenbaum, A. Hightower, C. C. Ahn, and B. Fultz, J. Electrochem. Soc. 146, 3963 (1999).

${ }^{15}$ S. Basu, G. K. Wertheim, and S. B. Dicenzo, in Lithium: Current Applications in Science, Medicine and Technology, edited by R. O. Bach (Wiley, New York, 1985), p. 187.

${ }^{16} \mathrm{~S}$. Ono, K. Hojou, and K. Kanaya, Proc. Fifth International Conference on High Voltage Electron Microscopy (Jap. Soc. Electron Microscopy, Kyoto, 1977), p. 481.

${ }^{17}$ L. W. Hobbs, in Quantitative Electron Microscopy, Proceedings of the 25th Scottish Universities Summer School in Physics, edited by J. N. Chapman and A. J. Craven (SUSSP, Edinburgh, 1983), p. 413.

${ }^{18}$ D. R. Liu and D. B. Williams, Philos. Mag. B 53, 123 (1986).

${ }^{19}$ K. R. Zavadil and N. R. Armstrong, Surf. Sci. 230, 47 (1990).

${ }^{20}$ M. M. Disko, in Analytical Electron Microscopy 1981, edited by R. H. Geiss (San Francisco Press, Inc., San Francisco, CA, 1981), p. 218.

${ }^{21}$ W. Shülke, K.-J. Gabriel, A. Berthold, and H. Schulte-Schrepping, Solid State Commun. 79, 657 (1991).

${ }^{22}$ T.-C. Chen, M. Qian, and T. G. Stoebe, J. Phys.: Condens. Matter 11, 341 (1999).

${ }^{23}$ K. R. Zavadil and N. R. Armstrong, Surf. Sci. 230, 47 (1990).

${ }^{24}$ J. R. Dahn, Phys. Rev. B 44, 9170 (1991). 